\title{
Strain Hardening Behavior of Laminate Structure With Stable bcc/fcc Bimetal Interfaces
}

\author{
Xuqiang Huang ${ }^{1 *}$, Zhaoyang $\mathrm{Lu}^{1}$, Minghui $\mathrm{Cai}^{2 *}$ and Peter D. Hodgson ${ }^{3}$ \\ ${ }^{1}$ School of Mechanical Engineering and Automation, Northeastern University, Shenyang, China, ${ }^{2}$ State Key Laboratory of Rolling \\ and Automation, Northeastern University, Shenyang, China, ${ }^{3}$ Institute for Frontier Materials (IFM), Deakin University, Geelong, VIC, \\ Australia
}

This work developed a well-bonded bcc/fcc bimetal interphase, which was produced by a two-step process involving diffusion bonding and conventional rolling. The high-quality interface maintained its integrity even at fracture. The earlier tensile instability in the core steel layer was constrained by the neighboring stable Cu layers on both sides, leading to extra strain hardening and consequently higher ductility. An increase in twin density or slip bands and shear deformation between the layers might be the primary causes for the observed hardening behaviors in the near-interface regions.

\section{OPEN ACCESS}

Edited by: Antonio Caggiano, Darmstadt University of Technology,

Germany

Reviewed by: Fuxing Yin,

Hebei University of Technology, China Yusheng Li,

Nanjing University of Science and

Technology, China

*Correspondence:

Xuqiang Huang

caimh@smm.neu.edu.cn

Specialty section: This article was submitted to

Structural Materials,

a section of the journal

Frontiers in Materials

Received: 03 September 2020 Accepted: 12 November 2020

Published: 07 December 2020

Citation:

Huang X, LuZ, Cai M and Hodgson PD (2020) Strain Hardening Behavior of Laminate Structure With Stable bcc/

fcc Bimetal Interfaces.

Front. Mater. 7:602441.

doi: 10.3389/fmats.2020.602441
Keywords: bimetal interface, strain hardening, nanoindentation, fracture, laminate structure

\section{INTRODUCTION}

A major motivation for manufacturing bimetal materials is to satisfy unique combinations of enhanced properties while reducing the overall cost (Zheng et al., 2013; Beyerlein et al., 2014a; Beyerlein et al., 2014b; Kong et al., 2019; Li et al., 2020; Zhao et al., 2020). So far, there have been attempts to reduce material costs by cladding a high strength mild steel plate in an anticorrosive material such as aluminium, copper, titanium, stainless steels, etc. (Yang et al., 1996; Gurgutlu et al., 2005; Zhang et al., 2011). Although conventional cladding technology, i.e., diffusion bonding, possesses great advantages for joining these dissimilar materials (Zhao et al., 2020), the technique is inappropriate for practical application, especially for large-scale structural materials such as sheets, in part due to the limited dimensions and lower productivity (Guo, 2015).

Alternatively, accumulative roll-bonding (ARB) (Saito et al., 1999) has been applied to examine the possibility of bonding dissimilar materials, including Ti/Al (Yang et al., 2010), Cu/Ag and Cu/Zr (Ohsaki et al., 2007), Al/Cu (Toroghinejad et al., 2013), with the aim of studying the influence of processing parameters on the interface microstructure and overall mechanical properties. Additionally, the study of bimetal interfaces has recently been of interest. For example, Ma et al. (Wu et al., 2014) explored a laminate nanostructured $(\mathrm{Cu}-\mathrm{Zn}) /$ coarse-grained (pure $\mathrm{Cu}$ ) structure, and investigated the influence of grain size difference across the interface on the mechanical behavior. It was found that the interface caused by tensile instability plays a crucial role in the overall strengthening and co-deformability of GS materials. Beyerlein et al. (Beyerlein et al., 2014a; Beyerlein et al., 2014b) and Zheng et al. (Zheng et al., 2013) demonstrated the emergence of a plastically and thermally stable $\mathrm{Cu}_{\mathrm{fcc}} / \mathrm{Nb}_{\mathrm{bcc}}$ interface during ARB. However, the deformation behavior of the bcc/fcc interface in these bimetallic materials during subsequent plastic deformation has yet to be fully investigated, even though it does play a crucial role in the overall strengthening and co-deformability (Beyerlein et al., 2012; Wu et al., 2014; Ma et al., 2015).

The aim of the present work is, therefore, to study the deformation behavior of a bcc/fcc bimetal interface in a tri-layered $\mathrm{Cu} / \mathrm{mild}$ steel/Cu laminate sheet, which is produced by combining diffusion 

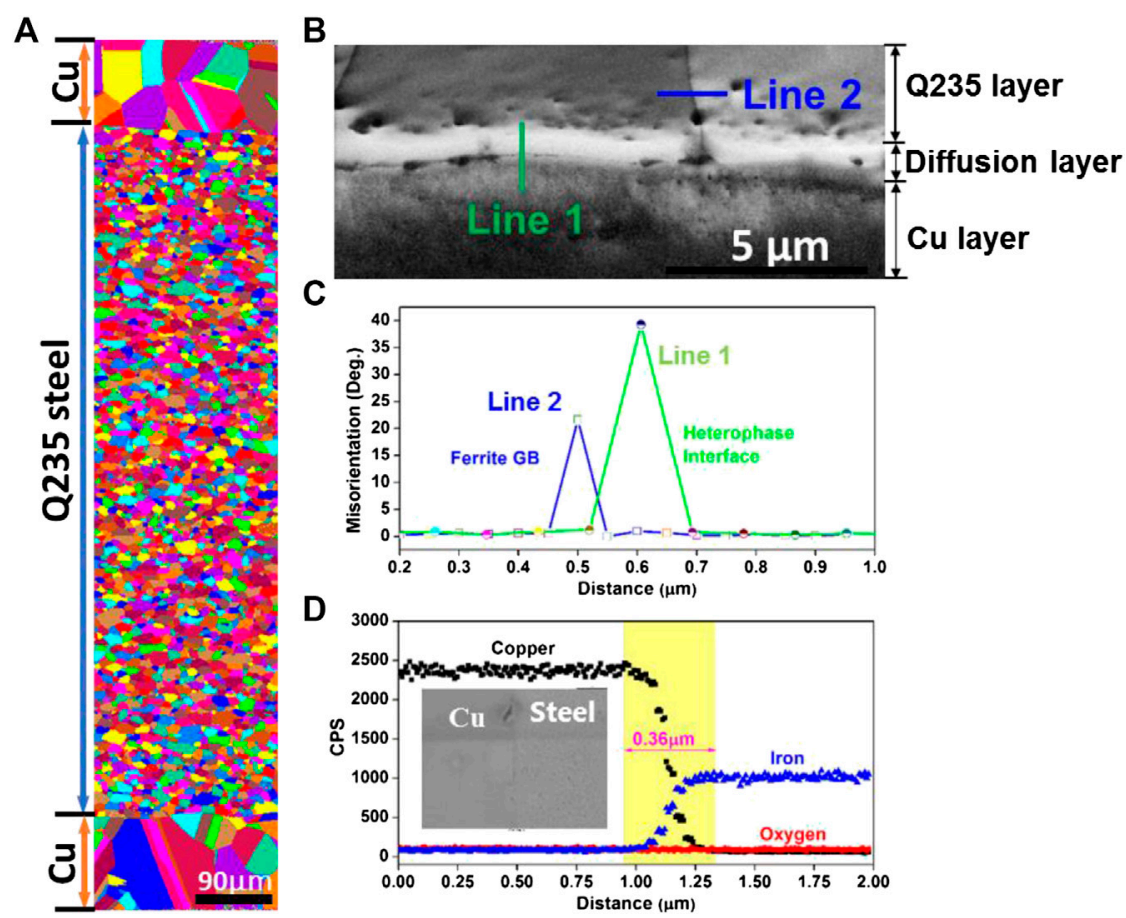

FIGURE 1|A representative cross-sectional structure of the tri-layered Cu/steel/Cu composite and interface features: (A) Unique grain color EBSD map indicating a copper-clad steel microstructure; (B) High-magnification image quality (IQ) map displaying a well-bonded Fe/Cu interface and three distinct zones; (C) Difference in misorientation angles between the ferrite grain boundary (GB) and the heterophase interface, corresponding to Line 1 and 2 in b, respectively; (D) An energy-dispersive X-ray Spectroscopy (EDX) profile showing elemental distribution of copper, iron and oxygen across the bond interface.

bonding with commercial rolling. Particular emphasis is placed on the fundamental understanding of the co-deformability and hardening behaviors between the layers through interrupted tensile testing coupled with nano-indentation.

\section{EXPERIMENTAL PROCEDURES}

Commercial pure copper $(\sim 10 \mathrm{~mm}$ thick $)$ and mild steel $(0.12 \mathrm{C}$ $0.3 \mathrm{Si}-0.4 \mathrm{Mn}, \sim 50 \mathrm{~mm}$ thick) plates were used to produce the trilayered $\mathrm{Cu} /$ steel/Cu laminate sheets. After a surface cleaning treatment, diffusion bonding was performed at $850^{\circ} \mathrm{C}$ and $20 \mathrm{MPa}$ in a protective Ar atmosphere to form a strong interfacial bond, followed by hot rolling to an overall thickness of $3.5 \mathrm{~mm}$ at $\sim 880^{\circ} \mathrm{C}$. After annealing at $\sim 800^{\circ} \mathrm{C}$ for $1 \mathrm{~h}$ and furnace cooling to room temperature, the laminate sheets were further cold rolled to $\sim 1 \mathrm{~mm}$ in one pass, perpendicular to the hot rolling direction.

A series of laminate samples with gauge dimension of $25 \times 6 \times$ $1 \mathrm{~mm}^{3}$ were cut from the rolled sheets. Interrupted tensile tests were performed to four different levels of strain, i.e., $6,13,20,24 \%$ (fracture) at a strain rate of $1.0 \times 10^{-4} \mathrm{~s}^{-1}$. Additionally, the pure $\mathrm{Cu}$ layers on both sides were removed by mechanical polishing to compare the core mild steel with the laminate sample under the same deformation conditions.

Microstructures and elemental mapping in the near-interface regions were characterized by a FEI Quanta 3D FEG-SEM with
TSL OIM EBSD and Electron Dispersive X-ray Spectroscopy (EDS) systems. Scanning electron microscopy (FEG-SEM; ZeissSupra $55 \mathrm{VP}$ ) was used to examine the fracture surface and interfacial features.

Nano-indentation measurements were carried out on all interrupted and fractured laminate samples using a Berkovich indenter at room temperature, based on the continuous stiffness measurement mode. A peak force of $0.5 \mathrm{mN}$ was applied with a constant loading rate of $5 \mu \mathrm{N} / \mathrm{s}$. The average hardness value of each point was determined using experimental raw data from at least 10 separate indents.

\section{RESULTS AND DISCUSSION}

Figure $\mathbf{1 A}$ is a cross-sectional EBSD map showing the typical microstructures, consisting of pure copper layers $(\sim 130 \mu \mathrm{m})$ on each side and a mild steel layer inside $(\sim 870 \mu \mathrm{m})$. Further analysis of a high-resolution EBSD image (Figure 1B) reveals that the initial bimetal interface exhibits a continuity of the bond and no dramatic crack or delamination is visible from the bcc Fe to fcc $\mathrm{Cu}$. The orientation profiles in Figure 1C demonstrate that the bimetal interface has much higher angle misorientations than the conventional ferrite grain boundary. The emergence of such a low-energy boundary structure probably leads to the excellent mechanical stability of the bimetal interface (Beyerlein et al., 2014a; Beyerlein et al., 2014b). The exact $\mathrm{Cu} / \mathrm{Fe}$ interface can be 

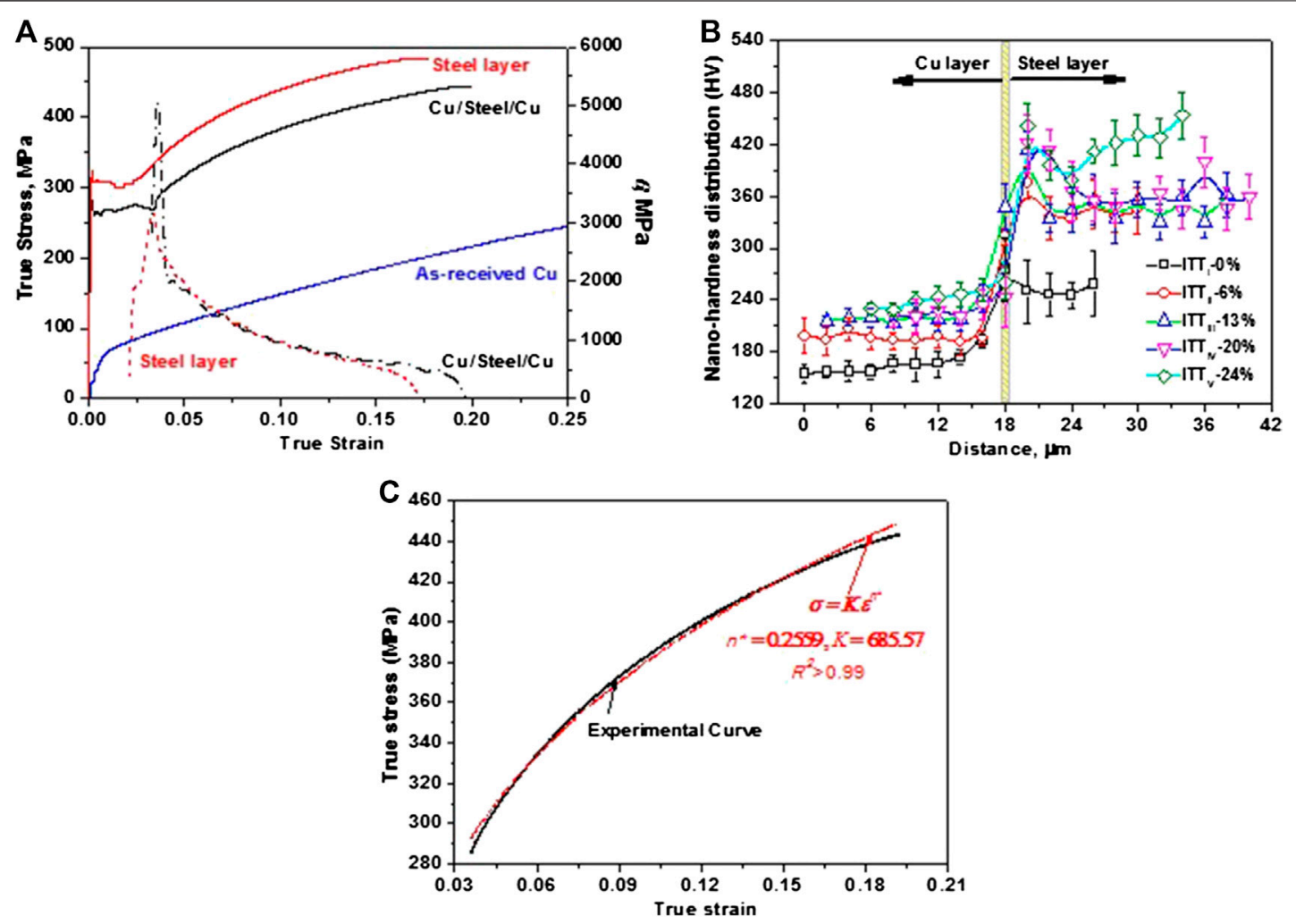

FIGURE 2 | (A) Representative true stress $(\sigma)$ and strain hardening rate, $\theta$ vs. true strain curves obtained at the strain rate of $10^{-4} \mathrm{~s}^{-1}$, in conjunction with interrupted tensile tests to 6\%, 13\% and 20\%, respectively; (B) Nano-hardness distribution profiles near the bimetal interface with applied strain, and error bars are determined from a range of experimental data (>10) on different rows with the same distance away from the interface; (C) Comparison of the experimental and fitted flow curves by Hollomon's equation. Here, $n^{*}$ is the average strain-hardening exponent, $K$ is the strength coefficient and $r^{2}$ is the correlation coefficient.

identified by EDS, Figure 1D. The elemental distribution profiles of $\mathrm{Fe}$ and $\mathrm{Cu}$ have relatively steep slopes, implying no significant bulk diffusion from each side during processing. As demonstrated in the Fe-Cu binary phase diagram (Atabaki et al., 2011), there is very limited solubility of $\mathrm{Fe}$ in $\mathrm{Cu}$, and the diffusion coefficient of $\mathrm{Cu}$ in $\mathrm{Fe}$ is very low (i.e., $1.3-2.4 \times 10^{-4} \mathrm{~cm}^{2} / \mathrm{s}$ ) even at a relatively high temperature (i.e., 1073-1173K) (Salje and FellerKniepmeier, 1977). Therefore, all of above characteristics confirm a well-bonded and sharp bcc/fcc bimetal interface.

Figure 2A shows the flow curves of the laminate samples interrupted at 6, 13, 20 and $24 \%$ (rupture), in conjunction with the steel layer after removing the pure $\mathrm{Cu}$ layers by mechanical polishing. One noteworthy feature of the stress-strain curves is that the overall yielding behavior is more like steel than $\mathrm{Cu}$. The tensile uniform elongation increases by $2.5 \%$ with a slight decrease in flow stresses by $\sim 40 \mathrm{MPa}$ when compared to the steel layer. Another important fact is that such laminate structures offer the exceptionally high tensile stress over the pure copper i.e. the yield stress is $\sim 4$ times as high, while minimizing material cost by using a cheap steel core.

During uniform deformation, the relationship between true stress and true strain of each component, i.e., bcc steel or fcc $\mathrm{Cu}$, can usually be described by the Hollomon equation $\sigma_{i}=k_{i} \varepsilon^{n i}$. It is found that there is relatively good agreement between the fitted and experimental curves (Figure 2C), probably due to relatively thinner and softer $\mathrm{Cu}$ layers when compared to the steel layer. However, the $n^{*}$ value predicted by Hollomon law is 0.256 , which is higher than the normal instantaneous $n$ value $(<0.2)$ of a conventional mild steel at room temperature. The higher $n$ value tends to restrict the onset of strain localization and the growth of sharp grain gradients.

Taking into account the negligible influence of thin $\mathrm{Cu}$ layers on the overall flow behavior of the laminate structure, the hardening behaviors are analyzed and compared with the steel layer using the curves of strain hardening rate $\left(\theta=d_{\sigma} / d \varepsilon\right)$ vs. true strain $(\varepsilon)$, Figure $\mathbf{2 A}$. In contrast, at the completion of a pronounced plateau in flow stress, the laminate sample exhibits an abrupt increase in stress with applied strain, corresponding to a stronger hardening capability with the maximum $\theta$ value of $\sim 5,000 \mathrm{MPa}$. Interestingly, the laminate sample behaves in a more typical manner showing a slower decrease in $\theta$ than the steel layer over a large stain range $(>0.1)$. The dramatic difference in hardening behaviors suggests that extra strain hardening is produced near the $\mathrm{bcc} / \mathrm{fcc}$ interfaces between the soft surface layers and hard middle layer.

A more detailed analysis of this hardening behavior has been performed utilizing a series of interrupted tensile tests coupled with nano-indentation. As is commonly observed the hardness $(H)$ values increase with the applied strain, Figure 2B. However, further analysis of the data reveals that the increment in hardness 
TABLE 1 | The increment in hardness of each individual layer as a function of the applied strain during tensile testing.

\begin{tabular}{ccccccc}
\hline Strain & & $\mathbf{0 \%}$ & $\mathbf{6 \%}$ & $\mathbf{1 3} \%$ & $\mathbf{2 0 \%}$ & $\mathbf{2 4 \%}$ (Fracture) \\
\hline Copper & $H_{O}$ & $162 \pm 7$ & $196 \pm 5$ & $218 \pm 4$ & $228 \pm 9$ & $243 \pm 11$ \\
& $\triangle H / H_{O}$ & 0 & $21 \%$ & $35 \%$ & $41 \%$ & $50 \%$ \\
Steel & $H$ & $250 \pm 6$ & $340 \pm 8$ & $345 \pm 13$ & $355 \pm 9$ & $418 \pm 14$ \\
& $\triangle H$ & 0 & $35.9 \%$ & $38.1 \%$ & $40.2 \%$ & $67.0 \%$
\end{tabular}

$(\triangle H)$ is closely related to various plastic deformation stages, as summarized in Table 1.

Even though the overall flow behavior will be dominated by the much thicker steel layer, it is still interesting to examine the hardness of the $\mathrm{Cu}$ layer. Using an increase in hardness to indicate an increase in strength, after straining to 0.058 (stage I), the $\mathrm{Cu}$ layer is strengthened by $\sim 21 \%$, while the increase is $\sim 36 \%$ for the steel layer. Even though both layers undergo relatively large strengthening at the initial stage, the hard steel layer is still the major contributor to the macroscopic strengthening compared to the soft $\mathrm{Cu}$ layer. Subsequently, the $\mathrm{Cu}$ layer exhibits stronger strengthening, with the relative increase in strength being equivalent to the steel layer at a true strain of 0.18 . The unique strengthening is consistent with the above analysis of strain hardening behavior in Figure 2A. In this case, the earlier tensile instability in the middle steel layer is constrained by the neighboring stable $\mathrm{Cu}$ layers on both sides. Actually, the mutual constraint between the layers adds extra strain hardening, and consequently enables the steel layer to uniformly deform further (Wu et al., 2009). This is also the reason why the laminate sample has a slower decrease in strain hardening rate than the middle steel layer with the applied strain $(>0.1)$. Therefore, the unstable steel layer needs to form an integral bulk with the stable $\mathrm{Cu}$ layers to be effective in producing extra strain hardening to postpone the onset of necking (Evans and Hirth, 1992; Gutierrez Urrutia and Raabe, 2012).

Typical microstructural evolution with tensile strain in the near-interface region has also been illustrated in Figure 3, where two levels of engineering strain, 13 and $24 \%$ are selected. After straining of $13 \%$, the $\mathrm{Cu}$ layer exhibits striations in the form of parallel packets that evolve preferentially in fcc grains with orientations close to $\langle 110\rangle$ and $\langle 111\rangle$, Figure 3A (annealing twinning). In contrast, the steel layer has slip bands that form in the $\langle 111\rangle$ and $\langle 001\rangle$ textured bcc grains, Figure 3B. The activation of additional twinning or slip systems during straining can be explained by the fact that irregular crystal rotations happen, especially in the regions adjacent to the bcc/ fcc interfaces, due to shear deformation (Figure 4C) by the mutual constraint between the soft and hard layers (Wu et al., 2009). With an increase in deformation strain to $24 \%$ (failure), there clearly exists the annealing twins (Figures 3C, 4), which act as an effective obstacle to dislocation movement and therefore decrease the ease of plastic deformation will strengthen the material. Therefore, it can be concluded that existence of annealing twins or an increase in slip bands during straining and shear phenomenon by the mutual constraint between the layers may be the primary causes for the observed strengthening in the near-interface regions.

The integrity of the bcc/fcc bimetal interface after tensile testing is examined by SEM, revealing a continuity of the
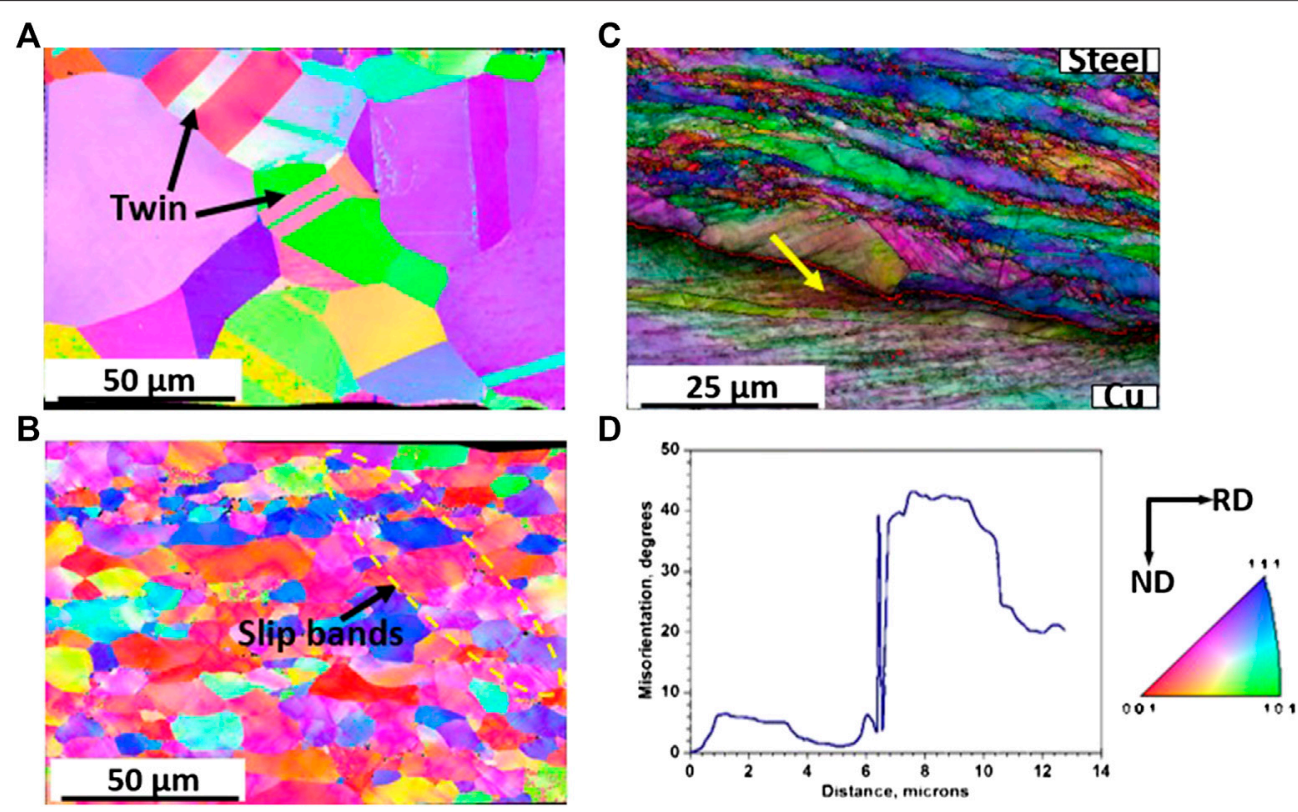

FIGURE 3 | Inverse pole figure maps showing the evolution of the cross-sectional microstructure with tensile deformation conditions: (A) fcc grains with twin boundaries in the Cu layer, and (B) bcc grains with slip bands after a tensile strain of 13\%; (C) fcc-bcc bimetal interface in the sample fractured at a tensile strain of $24 \%$. (D) shows a misorientation profile along the yellow line (C) cross the interface. 

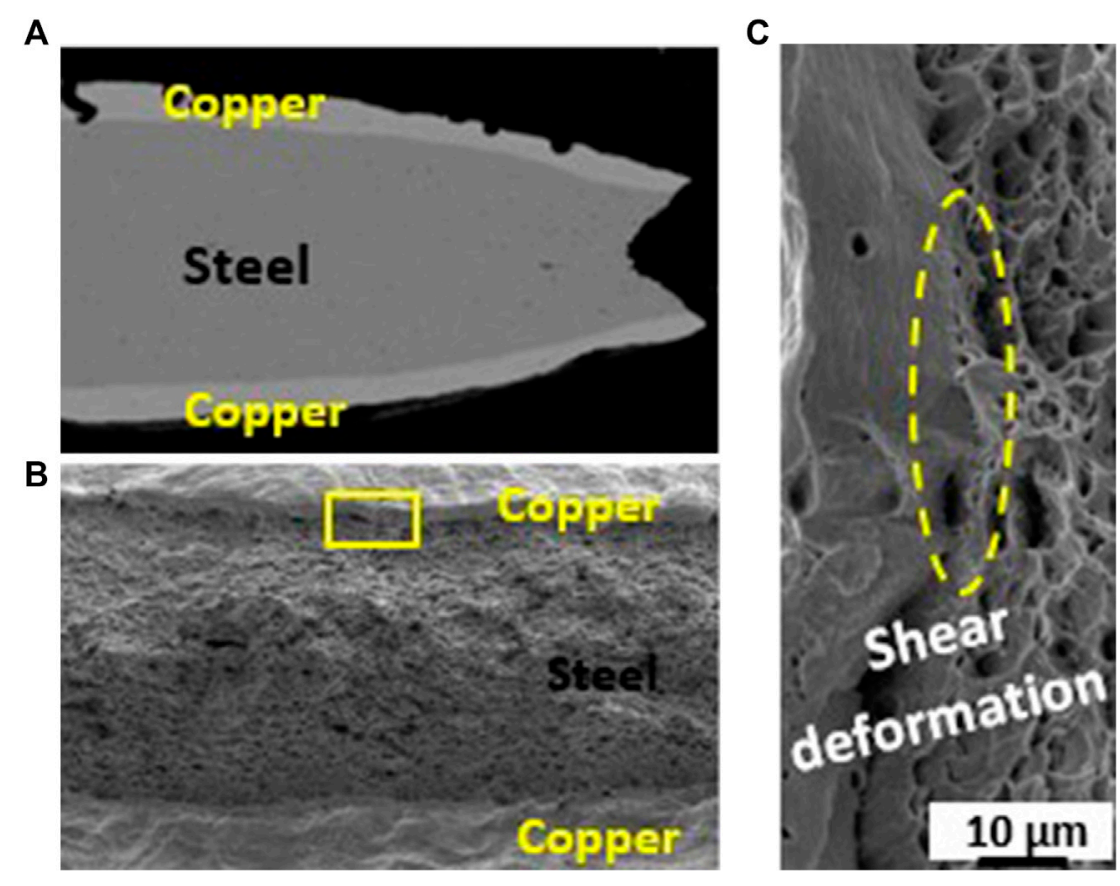

FIGURE 4 | Overview of SEM fractographs of the Cu/steel bimetal interface after tensile failure. (A) Representative morphology at the lateral fracture interface; (B) Overall fractograph after fracture and (C) Shear phenomenon between $\mathrm{Cu}$ and steel layers.

bond, i.e., no inner cracks or debonding over the entire deformation zone, Figure 4A. The fracture surface in Figure 4B demonstrates a typical dimple-like character in the near-interface regions, suggesting that the laminate samples fractures in a ductile manner. Another noteworthy feature of the fracture surface is shear deformation occurring between the interfaces, Figure 4C. The origin of the shear phenomenon is a result of the response to the mismatched tensile instabilities across the interfaces, and therefore, the mutual constraint between the soft and hard layers actually gives rise to extra strengthening. As a result, the earlier necking in the unstable steel layer may be quickly supressed by the neighboring stable $\mathrm{Cu}$ layers on both sides (Balke and De Hosson, 2001; Quadir et al., 2009; Wu et al., 2014; Ma et al., 2015; Liu et al., 2017; Liu et al., 2018).

\section{CONCLUSION}

In summary, a two-step process involving diffusion bonding and conventional rolling has been successfully applied to produce a well-bonded bcc/fcc bimetal interface. The laminate structure behaves in a more typical manner showing a slower decrease in $\theta$ than the steel layer over a large true strain range of $0.1-0.2$, implying extra strain hardening, and thus higher ductility. The newly developed laminate structure offers a much higher tensile stress over the pure copper i.e., the yield stress is $\sim 4$ times as high, while minimizing material cost by using a cheap steel core. An increase in twin density or slip bands and shear deformation by the mutual constraint between the layers may be the primary causes for the strengthening behaviors in the near-interface regions. Furthermore, the high-quality $\mathrm{bcc} / \mathrm{fcc}$ interface maintains its integrity even at fracture. This preliminary work indicates the well-bonded fcc/bcc bimetal interface plays a critical role in suppression of tensile instabilities of laminate composites.

\section{DATA AVAILABILITY STATEMENT}

The raw data supporting the conclusions of this article will be made available by the authors, without undue reservation.

\section{AUTHOR CONTRIBUTIONS}

$\mathrm{XH}$ : concept, writing, experiment; ZL: experiment; MC: writing, experiment; $\mathrm{PH}$ : supervision, modification.

\section{ACKNOWLEDGMENTS}

The present work was carried out with the support of the Deakin Advanced Characterization Facility. The authors gratefully acknowledge the financial support of the Natural Science Foundation of China (Grant Nos. 51975111/51671149) and the Fundamental Research Funding of the Central Universities, China (No. N2002002/N180702012). 


\section{REFERENCES}

Atabaki, M. M., Wati, J. N., and Idris, J. B. (2011). Proceedings of the 26th ASM heat treating society conference. Editors B. L. Ferguson, R. Jones, D. S. Mavkenzie, and D. Weires (United States: ASM International), 20-43.

Balke, P., and De Hosson, J. T. M., (2001). Orientation imaging microscopic observations of in situ deformed ultra low carbon steel. Scripta Mater. 44, 461-466. doi:10.1016/s1359-6462(00)00632-1

Beyerlein, I. J., Mara, N. A., Wang, J., Carpenter, J. S., Zheng, S. J., Han, W. Z., et al.(2012). Structure-property-functionality of bimetal interfaces. J. Occup. Med. 64, 1192-1207. doi:10.1007/s11837-012-0431-0

Beyerlein, I. J., Mayeur, J. R., Mccabe, R. J., Zheng, S. J., Carpenter, J. S., and Mara, N. A., (2014a). Influence of slip and twinning on the crystallographic stability of bimetal interfaces in nanocomposites under deformation. Acta Mater. 72, 137-147. doi:10.1016/j.actamat.2014.03.041

Beyerlein, I. J., Mayeur, J. R., Zheng, S., Mara, N. A., Wang, J., and Misra, A. (2014b). Emergence of stable interfaces under extreme plastic deformation. Proc. Natl. Acad. Sci. U. S. A. 111, 4386-4390. doi:10.1073/pnas.1319436111

Evans, A. G., and Hirth, J. P. (1992). Deformation of nanoscale cermets. Scripta Metall. Mater. 26, 1675-1680. doi:10.1016/0956-716x(92)90532-j

Guo, J. F. (2015). "Solid state welding processes in manufacturing, handbook of manufacturing engineering and technology," in Handbook of manufacturing engineering and technology. Editor A. Y. C. Nee (London: Springer), 569-592.

Gurgutlu, A., Gülenc, B., and Findik, F. (2005). Examination of copper/ stainless steel joints formed by explosive welding. Mater. Des. 26 497-507. doi:10.1016/j.matdes.2004.07.021

Gutierrez-Urrutia, I., and Raabe, D. (2012). Multistage strain hardening through dislocation substructure and twinning in a high strength and ductile weightreduced Fe-Mn-Al-C steel. Acta Mater. 60, 5791-5802. doi:10.1016/j.actamat. 2012.07.018

Kong, X. F., Beyerlein, I. J., Liu, Z. R., Yao, B. N., Legut, D., Germann, T. C., et al. (2019). Stronger and more failure-resistant with three-dimensional serrated bimetal interfaces. Acta Mater. 166, 231-245. doi:10.1016/j.actamat.2018.12.051

Li, Z., Zhao, J., Jia, F., Liang, X., Zhang, Q., Yuan, X., et al. (2020). Interfacial characteristics and mechanical properties of duplex stainless steel bimetal composite by heat treatment. Mater. Sci. Eng. 787, 139513. doi:10.1016/j. msea.2020.139513

Liu, B. X., Yin, F. X., Dai, X. L., He, J. N., Fang, W., Chen, C. X., et al. (2017). The tensile behaviors and fracture characteristics of stainless steel clad plates with different interfacial status. Mater. Sci. Eng. 679, 172-182. doi:10.1016/j.msea. 2016.10.033

Liu, B. X., Wei, J. Y., Yang, M. X., Yin, F. X., and Xu, K. C. (2018). Effect of heat treatment on the mechanical properties of copper clad steel plates. Vacuum 154 , 250-258. doi:10.1016/j.vacuum.2018.05.022

Ma, X. L., Huang, C. X., Xu, W. Z., Zhou, H., Wu, X. L., and Zhu, Y. T. (2015). Strain hardening and ductility in a coarse-grain/nanostructure laminate material. Scripta Mater. 103, 57-60. doi:10.1016/j.scriptamat.2015.03.006

Ohsaki, S., Kato, S., Tsuji, N., Ohkubo, T., and Hono, K. (2007). Bulk mechanical alloying of $\mathrm{Cu}-\mathrm{Ag}$ and $\mathrm{Cu} / \mathrm{Zr}$ two-phase microstructures by accumulative roll- bonding process. Acta Mater. 55, 2885-2895. doi:10.1016/j.actamat.2006.12. 027

Quadir, M. Z., Ferry, M., Al-Buhamad, O., and Munroe, P. R. (2009). Shear banding and recrystallization texture development in a multilayered $\mathrm{Al}$ alloy sheet produced by accumulative roll bonding. Acta Mater. 57, 29-40. doi:10. 1016/j.actamat.2008.08.056

Saito, Y., Utsunomiya, H., Tsuji, N., and Sakai, T. (1999). Novel ultra-high straining process for bulk materials-development of the accumulative roll-bonding (ARB) process. Acta Mater. 47, 579-583. doi:10.1016/s1359-6454(98)00365-6

Salje, G., and Feller-Kniepmeier, M. (1977). The diffusion and solubility of copper in iron. J. Appl. Phys. 48, 1833-1839. doi:10.1063/1.323934

Toroghinejad, M. R., Jamaati, R., Dutkiewicz, J., and Szpunar, J. A. (2013). Investigation of nanostructured aluminum/copper composite produced by accumulative roll bonding and folding process. Mater. Des. 51, 274-279. doi:10.1016/j.matdes.2013.04.002

Wu, X. L., Jiang, P., Chen, L., Yuan, F. P., and Zhu, Y. T. (2014). Extraordinary strain hardening by gradient structure. Proc. Natl. Acad. Sci. U.S.A. 111, 7197-7201. doi:10.1073/pnas.1324069111

Wu, X. L., Zhu, Y. T., Wei, Q., and Wei, Y. G. (2009). Strong Strain Hardening in Nanocrystalline Nickel. Phys. Rev. Lett. 103, 205504. doi:10.1103/physrevlett. 103.205504

Yang, D., Cizek, P., Hodgson, P., and Wen, C. E. (2010). Ultrafine equiaxed-grain $\mathrm{Ti} / \mathrm{Al}$ composite produced by accumulative roll bonding. Scripta Mater. 62, 321-324. doi:10.1016/j.scriptamat.2009.11.036

Yang, Y., Xinming, Z., Zhenghua, L., and Qingyun, L. (1996). Adiabatic shear band on the titanium side in the $\mathrm{Ti} / \mathrm{mild}$ steel explosive cladding interface. Acto Mater. 44, 561-565. doi:10.1016/1359-6454(95)00200-6

Zhang, G., Su, W., Zhang, J., and Wei, Z., (2011). Friction stir brazing: a novel process for fabricating $\mathrm{Al} /$ steel layered composite and for dissimilar joining of Al to steel. Metall. Mater. Trans. 42, 2850-2861. doi:10.1007/s11661-011-06770

Zhao, K. N., Xu, D. X., Li, H. X., Wang, J., Ma, Y. Z., and Zhang, J. S. (2020). Fabrication, microstructure, and properties of interface-reinforced $\mathrm{Mg} / \mathrm{Mg}$ bimetal composites by long-period stacking ordered structures. J. Alloys Compd. 816, 152526. doi:10.1016/j.jallcom.2019.152526

Zheng, S. J., Beyerlein, I. J., Carpenter, J. S., Kang, K., Wang, J., Han, W. Z., et al. (2013). High-strength and thermally stable bulk nanolayered composites due to twin-induced interfaces. Nat. Commun. 4, 1-8. doi:10.1038/ncomms2651

Conflict of Interest: The authors declare that the research was conducted in the absence of any commercial or financial relationships that could be construed as a potential conflict of interest.

Copyright (c) 2020 Huang, Lv, Cai and Hodgson. This is an open-access article distributed under the terms of the Creative Commons Attribution License (CC BY). The use, distribution or reproduction in other forums is permitted, provided the original author(s) and the copyright owner(s) are credited and that the original publication in this journal is cited, in accordance with accepted academic practice. No use, distribution or reproduction is permitted which does not comply with these terms. 